\title{
Spot Form of Net Blotch Resistance in a Diverse Set of Barley Lines in Australia and Canada
}

Mark S. McLean, BioSciences Research, Department of Primary Industries, Horsham, VIC, 3401, Australia, and School of Botany, The University of Melbourne, VIC, 3010, Australia; Barbara J. Howlett, School of Botany, The University of Melbourne, Australia; T. Kelly Turkington, Lacombe Research Centre, Agriculture and Agri-food Canada, Lacombe, AB, T4L 1W1, Canada; Greg J. Platz, Department of Employment, Economic Development and Innovation, Warwick, QLD, 4370, Australia; and Grant J. Hollaway, BioSciences Research, Department of Primary Industries, Horsham, Australia

\begin{abstract}
McLean, M. S., Howlett, B. J., Turkington, T. K., Platz, G. J., and Hollaway, G. J. 2012. Spot form of net blotch resistance in a diverse set of barley lines in Australia and Canada. Plant Dis. 96:569-576.

The responses of 95 barley lines and cultivars to spot form of net blotch (SFNB) caused by Pyrenophora teres f. maculata were analyzed as seedlings and adults in Australia and Canada. Cluster analyses revealed complex reaction responses. Only 2 lines (Esperance Orge 289 and TR3189) were resistant to all isolates at the seedling stage, whereas 15 lines and cultivars (81-82/033, Arimont, BYDV-018, CBSS97M00855T-B2-M1-Y1-M2-Y-1M-0Y, CI9776, Keel, Sloop, Torrens, TR326, VB0111, Yarra, VB0229, WI-2477, WI2553, and Wisconsin Pedigree) were resistant toward the two Canadian isolates and mixture of Australian isolates at the adult stages. In Australian

field experiments, the effectiveness of SFNB resistance in three barley cultivars (Barque, Cowabbie, and Schooner) and one breeding line (VB9104) with a different source of resistance was tested. Barque, which possessed a resistance gene that provided complete resistance to SFNB, was the most effective and showed no effect on grain yield or quality in the presence of inoculum. Generally, cultivars with seedling or adult resistance had less disease and better grain quality than the susceptible control, Dash, but they were not as effective as Barque. A preliminary differential set of 19 barley lines and cultivars for $P$. teres f. maculata is proposed.
\end{abstract}

Spot form of net blotch (SFNB) caused by Pyrenophora teres $\mathrm{f}$. maculata Smed.-Pet. is a major foliar disease of barley (Hordeum vulgare L.) worldwide (14) and is currently the most prevalent foliar disease of barley in Victoria, Australia (15). The prevalence of SFNB is due to the adoption of stubble-retention practices, high intensity of barley in cropping rotations, and predominantly susceptible cultivars being cultivated. The severity of SFNB is highly variable and depends on factors such as local climate, amount of inoculum present, and the resistance of the barley cultivar being sown. When SFNB is severe, it can reduce grain yield by up to $44 \%$ and grain quality parameters such as 1,000-grain-weight by up to $19 \%$ (10).

Management strategies for SFNB include the application of foliar fungicide, crop rotation, stubble destruction, and cultivation of resistant cultivars (14). Cultivation of disease-resistant barley cultivars is the most favorable strategy because it eliminates the need for additional disease control measures and the added input costs they may incur. Even a moderately susceptible cultivar can provide sufficient control of SFNB, such that fungicide application is unnecessary (21). At least 11 different sources of host-plant resistance to SFNB have been characterized while many others have been identified in barley germplasm worldwide (14). These resistances are typically conferred by multiple genes that can be either of major or minor effect, located in one region of a single chromosome, such as those identified for the Rpt4 gene and Ha4 allele $(22,23)$; or, as is more common, located on several chromo-

Corresponding author: M. S. McLean,

E-mail: mark.mclean@dpi.vic.gov.au

* The $e$-Xtra logo stands for "electronic extra" and indicates that a supplemental table is available in the online edition.

Accepted for publication 7 November 2011.

http://dx.doi.org/10.1094/PDIS-06-11-0477

(C) 2012 The American Phytopathological Society somes. Unfortunately, few of these resistance genes have been incorporated into malt-quality barley cultivars in Australia and Canada and, as a consequence, the majority of cultivars are susceptible to SFNB. In Australia, some feed barley cultivars do, however, have resistance genes. These are primarily from two sources: the Rpt4 gene, which is located on chromosome $7 \mathrm{H}$ in 'Keel' and breeding lines Galleon, Tilga, and CI9214 (22,23), and the Ha4 allele for cereal cyst nematode (Heterodera avenae) resistance, which also confers resistance to SFNB (23). Other sources of resistance have also been identified in Australian barley germplasm and included in cultivars but are yet to be characterized genetically (14). Each resistance source varies in its effectiveness and, in general, there are two types of resistance to SFNB present in barley germplasm. The first provides resistance during a particular stage of growth of the plant while the second provides total or complete resistance effective for the entire life of the plant. The Rpt 4 gene is only effective at the seedling stage, whereas other resistance genes are primarily effective at adult stages of plant development $(22,23)$. Resistance genes associated with seedling or adult resistance can provide moderate resistance to SFNB leading to considerable reductions in disease severity (21). However, it is currently not known whether barley cultivars possessing resistance genes that confer seedling or adult plant resistance provide adequate control of SFNB in Australian environmental conditions.

$P$. teres f. maculata is able to sexually reproduce and is pathogenically variable with different pathotypes within and between barley growing regions $(2-4,7,11,12,20)$. This variability provides a significant challenge for barley breeders because a given resistance source may be effective only toward specific pathotypes. Manninen et al. (13) found that barley lines with the resistance gene Rpt6 provided a resistant response to Finnish but not Australian isolates. There is an inadequate understanding of the pathotypes of $P$. teres $\mathrm{f}$. maculata worldwide because the majority of reports are more than a decade old. Furthermore, previous studies have focused on local breeding lines and a limited number of pathotypes. The development of a standard set of differential barley lines, as exists for Pyrenophora teres f. teres Drechsler (1), is required for $P$. teres f. maculata to provide a standard 
method of discriminating pathotypes in the worldwide pathogen population.

The objectives of this study were to (i) identify sources of SFNB resistance in barley lines and cultivars for inclusion in barley breeding programs, (ii) establish a basis for the development of an international differential set of barley lines for P. teres f. maculata, and (iii) determine whether resistances expressed at seedling and adult stages provide adequate SFNB control under Australian field conditions.

To accomplish these objectives, the phenotypic responses of 92 barley lines with diverse genetic backgrounds were investigated against Australian and Canadian pathotypes of $P$. teres $\mathrm{f}$. maculata. In addition, the effectiveness of three different barley cultivars and one breeding line from Australia that possess resistance genes partially effective at either the seedling or adult stages was determined in the field in the Wimmera region of Victoria, Australia.

\section{Materials and Methods}

Barley breeding lines. Ninety-five barley lines and cultivars were tested in the field as adults and in the glasshouse as seedlings. The lines and cultivars were chosen based on SFNB resistance data from studies reported by Khan (12), Bockleman et al. (4), Karki and Sharp (11), Tekauz (20), Arabi et al. (3), Gupta and Loughman (7), Arabi et al. (2), and G. Platz (unpublished data) and personal communications with S. Gupta (Department of Agriculture and Food Western Australia) and D. Moody (Department of Primary Industries Victoria). Three susceptible cultivars ('Dash', 'Gairdner', and 'Kombar') were included. Lines and cultivars were tested in Australia and Canada to obtain information on P. teres f. maculata isolates from diverse pathogen populations without the risk of spreading exotic pathotypes.

Screening of barley lines in field disease nurseries. The 95 barley lines and cultivars were evaluated for their response to $P$. teres f. maculata at adult crop growth stages at two sites in 2008. The first site was located approximately $7 \mathrm{~km}$ east of Horsham, Australia (S 36.7396, E 142.1165). The site had an average annual rainfall of $445 \mathrm{~mm}$ and was sown into a flood irrigation bay, which had been sown to faba beans (Vicia faba L.) in the previous year with no barley stubble on the soil surface. Prior to sowing, the site was cultivated and $100 \mathrm{~kg} / \mathrm{ha}$ of MAP fertilizer (N, 10\%; P, 21.9\%; and S, 1.5\%; Incitec Pivot Ltd.) was incorporated into the soil. The nursery was sown on 21 May 2008 in a nonreplicated randomized design. Approximately 10 seeds of each barley line and cultivar were sown as an individual hill plot $1 \mathrm{~m}$ in length, with approximately $40 \mathrm{~cm}$ between rows and $20 \mathrm{~cm}$ between each hill plot within each row. Spreader rows of the susceptible barley Dash were sown around the nursery. Barley stubble naturally infected with $P$. teres $\mathrm{f}$. maculata was applied to the nursery on 10 June 2008 to establish seedling infection. The infected stubble was collected from a crop of Gairdner barley located in a nearby farmer's field and probably included a mixture of pathotypes of $P$. teres $\mathrm{f}$. maculata.

Weeds were managed at the Horsham disease nursery with trifuralin $(480 \mathrm{~g} / \mathrm{liter})$ applied at $800 \mathrm{ml} / \mathrm{ha}$; a mixture of prosulfocarb (800 g/liter) and S-metholachlor (120 g/liter) applied at 2 liters/ha on 23 May; a mixture of pinoxaden (100 g/liter) and cloquintocetmexyl ( $25 \mathrm{~g} / \mathrm{liter})$ applied at $300 \mathrm{ml} / \mathrm{ha}$ on $15 \mathrm{June}$; a mixture of MCPA (280 g/liter), bromoxynil (140 g/liter), and dicamba (40 g/liter) applied at 1.2 liters/ha on 3 July and 20 August; and tralkoxydin (400 g/liter) applied at $500 \mathrm{ml} / \mathrm{ha}$ on $19 \mathrm{July}$. All herbicides were applied with a water volume of 80 liters/ha. Aphids were managed using ethidathion (400 g/liter) applied at $800 \mathrm{ml} / \mathrm{ha}$ on 29 September. The site was flood irrigated in order to prolong the growing season and disease infection and delay senescence.

The second site had an average annual rainfall of $430 \mathrm{~mm}$ and was located at Lacombe, Alberta, Canada (S 52.4505, E 113.7313). The barley lines and cultivars were sown into a field that had been sown with canola in the previous season, with no barley stubble present on the soil surface. Prior to sowing, the site was cultivated and $36 \mathrm{~kg} / \mathrm{ha}$ of NPKS fertilizer (N, 15\%; P, 11\%; K, 11\%; and S,
$1 \%$ ) was incorporated into the soil. Two separate nurseries inoculated with different isolates of $P$. teres f. maculata were established. Four replicates of each individual line and cultivar was sown as hill plots with approximately 10 seeds/hill in a randomized design on 29 May 2008. Hill plots were arranged in rows with approximately $46 \mathrm{~cm}$ between rows and $46 \mathrm{~cm}$ between hill plots within rows. Spreader rows of 'Seebe' were sown on either side of every three rows of test material. Weeds were managed at the nurseries at Lacombe using a mixture of pyrasulfotole $(37.5 \mathrm{~g} /$ liter $)$ and bromoxynil (210 g/liter) applied at $828 \mathrm{ml} / \mathrm{ha}$ and fenoxaprop-pethyl (120 g/liter) applied at $771 \mathrm{ml} / \mathrm{ha}$. All herbicides were applied with a water volume of 96 liters/ha on 13 June. Due to a lack of barley stubble naturally infected with $P$. teres f. maculata occurring in the Lacombe area, each Lacombe nursery was inoculated on 26 June 2008 with sterilized wheat seed that had been artificially inoculated with two individual isolates (Dillon and 857WRS) of $P$. teres f. maculata that had been derived from single spores. The first isolate, called Dillon, was from 'Dillon' barley in Alberta, while the second isolate, called 857WRS, was collected from barley line $857 \mathrm{WRS}$ and provided by Dr. A. Tekauz (Agriculture and Agri-Food Canada, Winnipeg, MB, Canada). For inoculum production, wheat seed was placed in an autoclave bag, soaked in water overnight, drained, and then autoclaved for 45 to $60 \mathrm{~min}$ at $15 \mathrm{psi}$ and $121^{\circ} \mathrm{C}$. The autoclaved seed was then cooled and, after $24 \mathrm{~h}$, approximately 20 to $25 \mathrm{ml}$ of reverse-osmosis water was added to each bag of grain, followed by autoclaving for 45 to $60 \mathrm{~min}$ at 15 psi and $121^{\circ} \mathrm{C}$. The grain was then left to cool before being inoculated with one of two single-spore-derived isolates (Dillon and 857WRS) of P. teres f. maculata. Each isolate was cultured on V8 juice agar (20\% Campbell's V8 vegetable juice agar containing $0.4 \%$ calcium carbonate) for 7 to 10 days. Cultures of both isolates were cut into approximately $0.5-$ by $-0.5-\mathrm{cm}$ pieces and added to one lot of wheat seed, then sealed in plastic bags. The wheat seed and $P$. teres f. maculata culture pieces were then shaken to distribute culture pieces throughout the moistened sterile wheat seed. The inoculated wheat seed were then incubated at 20 to $22^{\circ} \mathrm{C}$ for 2 to 3 weeks until completely colonized. The colonized wheat seed were then dried at room temperature and separated into individual colonized wheat seed. Approximately $4.6 \mathrm{~g}$ of wheat seed inoculum was used to inoculate each individual hill plot.

Each barley line and cultivar was assessed for lesion severity consistent with SFNB symptoms based on a 1-to-9 scale developed by Tekauz (19), where small, dark-brown necrotic lesions with no chlorosis were scored 1 to 4 ; medium, dark-brown lesions with some chlorosis were scored 5 to 6; and large, dark-brown lesions with severe chlorosis were scored 7 to 9. Assessment dates and crop growth stages were noted. Barley lines and cultivars were assessed four times at Lacombe (22 July, 28 July, 8 August, and 12 August) and five times at Horsham (4 September, 23 September, 7 October, 22 October, and 24 October). To confirm the causal agent as $P$. teres f. maculata, 10 leaf samples showing symptoms consistent with that of SFNB were collected and surface sterilized in $70 \%$ ethanol for $10 \mathrm{~s}$ and $1 \%$ bleach solution for $30 \mathrm{~s}$, then rinsed in sterile distilled water for $10 \mathrm{~s}$. Sterilized leaf pieces were then placed onto potato dextrose agar (3.9\%; Oxoid) containing streptomycin sulfate $(0.39 \%)$ and incubated at $20^{\circ} \mathrm{C}$ under diurnal florescent, near-UV and growlux lights with a 12 -h photoperiod to produce spores, which were then observed microscopically.

Screening of barley lines as seedlings in glasshouse. The reaction responses of the 95 barley lines and cultivars were determined as seedlings toward 10 individual Australian isolates (SNB113, SNB263, SNB281, HRS06022, WAC9238, WAC11153, 03/05, 5/98/4, 04-0018, and 04-0073) of P. teres f. maculata at Horsham, Victoria, Australia and nine Canadian isolates (LO262, LO233, 857WRS, TR473, TR253, LEDUC, CDC Trey, AOC21, and CI5791) at Lacombe, Alberta, Canada. For each country, isolates represented a range of geographically dispersed locations across respective barley-growing regions.

At Horsham, four replicates of each line and cultivar were sown in a randomized complete block design. For each individual line 
and cultivar, two seeds were sown into a 6-cm pot filled with potting mix supplemented with nutrients (trace elements, isobutylidene diurea, slow-release fertilizer, lime, and iron). At Lacombe, five replicates of each line and cultivar were sown in a randomized complete block design. For each individual line and cultivar, two seeds were sown into a $15-\mathrm{cm}$ pot filled with peat mix ( 80 to $85 \%$ ), vermiculite, perlite, and dolomitic and calcitic limestone, supplemented with micronutrients, macronutrients, and slow-release fertilizer. At both sites, seedlings were grown to the two- to three-leaf stage (12 to 15 days) in a glasshouse at 15 to $20^{\circ} \mathrm{C}$. Seedlings were inoculated with a spore and mycelium suspension derived from 9- to 12-day-old $P$. teres f. maculata cultures grown on $20 \%$ Campbell's V8 vegetable juice agar containing $0.4 \%$ calcium carbonate. The spore and mycelium suspension was prepared by adding $4 \mathrm{ml}$ of sterile water to each plate, scraping the agar surface with a sterile metal utensil, then filtering the solution through a sieve or cheese cloth. The subsequent suspension was adjusted to $2 \times 10^{4}$ conidia and mycelium per milliliter and two drops of Tween 20 per milliliter was added. The suspension was sprayed onto seedlings until leaves were wet. Inoculated seedlings were then placed in a controlled-environment room. At Horsham, seedlings were kept at 95 to $100 \%$ humidity at $20^{\circ} \mathrm{C}$ for $48 \mathrm{~h}$, with the first $24 \mathrm{~h}$ in darkness. At Lacombe, seedlings were kept at 95 to $100 \%$ humidity at $20 \pm 5^{\circ} \mathrm{C}$ for $24 \mathrm{~h}$ in darkness. At both sites, symptoms were allowed to develop for a further 7 to 9 days at $20^{\circ} \mathrm{C}$ under a 12 -h photoperiod. Plants were then assessed visually for lesion severity based on the 1-to-9 scale developed by Tekauz (19), as described above.

Impact of seedling, adult, and complete resistance on SFNB severity in the field and subsequent grain yield and quality. Three cultivars ('Barque', 'Cowabbie', and 'Schooner') and one breeding line (VB9104) with known SFNB resistance and a susceptible control (Dash) were evaluated for SFNB severity and subsequent grain yield and quality in the field. The cultivars and breeding line possessed different sources of resistance which were effective at different crop growth stages. Barque has resistance that remains effective throughout the life of the plant, Cowabbie and Schooner have seedling resistance, and VB9104 has adult resistance (unpublished data). These cultivars and breeding line were sown in field experiments established $7 \mathrm{~km}$ east of Horsham at the site described above, and $22 \mathrm{~km}$ south of Horsham at Wonwondah (S36.860807, E 142.144504) in 2007, and again at Wonwondah in 2008. Barley stubble residue naturally infected with $P$. teres $\mathrm{f}$. maculata was present at Horsham in 2007 but not at Wonwondah.

Prior to sowing, seed was treated with tebuconazole $(25 \mathrm{~g}$ a.i./liter) and triflumuron ( $4 \mathrm{~g}$ a.i./liter) at $1 \mathrm{ml} / \mathrm{kg}$ to control seedborne smut diseases. Plots were sown with seed at $70 \mathrm{~kg} / \mathrm{ha}$ with MAP fertilizer (N, 10\%; P, 21.9\%; and S, 1.5\%; Incitec Pivot Ltd.) at $100 \mathrm{~kg} / \mathrm{ha}$.

For each of the cultivars and breeding line, two separate treatments were applied: (i) maximum disease plots, which consisted of applying barley stubble naturally infected with $P$. teres f. maculata at $3 \mathrm{t} / \mathrm{ha}$ and no foliar fungicide applied; and (ii) minimum disease plots, which consisted of uninfected wheat stubble at $3 \mathrm{t} / \mathrm{ha}$ and applications of foliar fungicide (propiconazole applied at $62.5 \mathrm{~g}$ a.i./ha with $40 \mathrm{psi}$ ) at 14- to 18-day intervals, starting at seedling stage and finishing at plant senescence. Differences in grain yield and quality between these two treatments were used to calculate losses in grain yield and quality due to disease. At Wonwondah in 2008, no wheat stubble was applied to the plots treated with foliar fungicide. Both barley and wheat stubbles were collected from nearby fields sown in the previous year. Six replicates of each treatment of the barley cultivars and breeding line were sown in randomized complete block designs. Each plot consisted of 12 rows, $2.6 \mathrm{~m}$ in width and $10 \mathrm{~m}$ in length. A six-row wheat plot was sown parallel as a buffer between each barley plot to minimize interplot interference. Weeds and insects were managed using the same herbicides and insecticides mentioned above for Horsham.

Each barley plot was assessed four times at the Wonwondah sites and three times at the Horsham site. Percent leaf area affected by each disease was visually estimated on the top four leaves (flag, flag-1, flag-2, and flag-3) of 10 arbitrarily selected tillers. Plant growth stage was noted according to Zadocks' decimal code (25). Grain yield was determined for each plot by harvesting the grain with a plot harvester when plants were senesced. The 1,000-grainweight was determined by weighing 200 grains and multiplying by five. Screenings and retention were estimated by weighing the percentage of grain below $2.2 \mathrm{~mm}$ and above $2.5 \mathrm{~mm}$ in width, respectively, in a $100-\mathrm{g}$ subsample of the harvested grain. Percent protein content was determined for the stubble and fungicide treatments of Dash using near-infrared analysis (18). No significant differences in protein content were detected between stubble and fungicide treatments of Dash, which indicated that further protein analysis of Barque, Cowabbie, Schooner, and VB9104 was not necessary.

Statistical analyses: reaction response of barley lines toward $P$. teres $f$. maculata. Average disease scores were calculated for all lines and cultivars as seedlings and adults. For statistical analysis of the average disease scores, separate similarity matrices of the 95 barley lines and cultivars were constructed for reactions toward isolates at the seedling and adult plant stages. Disease scores were converted to a reaction response (scores 1 to $5=$ resistant and 6 to $9=$ susceptible) and similarity matrices were constructed. The two similarity matrices were then used to perform cluster analysis using the unweighted pair-group method with arithmetic means (UPGMA) procedure. The program MVSP 3.1 was used to construct the Jaccard similarity matrix and perform the UPGMA analysis.

Pathotypes were designated for the 19 isolates of $P$. teres $\mathrm{f}$. maculata using the converted seedling reaction response data mentioned above. A subset of 25 barley lines and cultivars was used that represented the various groupings from the above-mentioned cluster analysis. The program HaGiS (8) that exploits Microsoft Excel was used. Correlation coefficients and $P$ values were estimated between seedling and adult scores, adult scores between sites, and seedlings between sites using GenStat, 13th Edition.

Statistical analyses: SFNB severity, grain yield, and grain quality. To assess the effect of the barley cultivars and breeding line with different sources of resistance to $P$. teres f. maculata, average SFNB severity was determined and area under the disease progress curves (AUDPC) calculated (17). Treatment impacts on average SFNB severity, AUDPC, retention, screenings, 1,000grain-weight, and grain yield were determined using analysis of variance (ANOVA) in GenStat, and treatment differences were determined at 5\% significance level. Cultivar effect on SFNB severity and AUDPC were also determined using ANOVA in GenStat at the 5\% significance level.

\section{Results}

Resistance response of seedlings to $P$. teres $f$. maculata in the glasshouse. On susceptible lines, virulent $P$. teres f. maculata isolates produced symptoms initially characterized by small, darkbrown pinpoint-sized lesions $1 \mathrm{~mm}$ in diameter within $48 \mathrm{~h}$ of inoculation. These necrotic lesions developed rapidly to approximately $4 \mathrm{~mm}$ in size, round in shape, and dark brown in color, and were surrounded by chlorosis within a week. For nonvirulent isolates and resistant lines, small, dark-brown, pinpoint-sized lesions were observed within 5 days of inoculation. These lesions did not increase in size. Average SFNB severity rating ranged between 2 and 8 in the 95 barley lines and cultivars tested.

Two lines (Esperance Orge 289 and TR3189) were resistant to all 19 isolates as seedlings (Supplementary Table 1) and fell into a separate group (Fig. 1, group 11) based on UPGMA analysis. Twenty-eight lines fell into groups 1, 8, 9, and 10 and were generally moderately resistant. Nineteen lines fell into groups 2 and 3 and ranged from moderately resistant to moderate susceptible. Twenty-six lines fell into groups 4,5 , and 7 and were typically moderately susceptible. Eighteen lines fell into group 6 and were susceptible to most of the 19 isolates. Seventeen lines were resistant to all of the Australian isolates but responded differentially toward the Canadian isolates, with either resistant or susceptible 
responses. Fifty-two lines responded differentially to Australian and Canadian isolates. Twenty-two lines were susceptible to the Australian isolates and showed differential responses toward the Canadian isolates. Two lines, Gairdner and Kombar, were susceptible to all isolates.

Resistance response of barley lines in the field. SFNB development was different between the Australian and Canadian field nurseries. At Horsham, a low to moderate level of infection was established early in the winter months that progressed rapidly during the spring months. The majority of the upper leaves of susceptible cultivars were infected with SFNB. A low to moderate level of scald (caused by Rhynchosporium secalis (Oudem) Davis) and a low level of leaf rust (caused by Puccinia hordei G.H. Otth) were also present. At Lacombe, a low level of Pyrenophora teres $\mathrm{f}$. maculata infection was established during July and developed slowly throughout the summer compared with Horsham. Low to moderate levels of $P$. teres $\mathrm{f}$. maculata infection were apparent on the upper leaves at crop senescence. At both sites, resistant lines developed small, pinpoint-sized dark-brown lesions. Susceptible lines developed large, dark-brown necrotic lesions with yellow chlorosis, while lesions of intermediate size were also detected.

Fifteen lines (81-82/033, Arimont, BYDV-018, CBSS97M00855TB2-M1-Y1-M2-Y-1M-0Y, CI9776, Keel, Sloop, Torrens, TR326, Yarra, VB0111, VB0229, WI2477, WI2553, and Wisconsin Pedigree) were resistant to the Australian and Canadian isolates tested in the field. In all, 56 lines were resistant to the Australian isolates but susceptible to at least one of the Canadian isolates, while 17 were susceptible to all isolates. Three barley lines were resistant to the Canadian isolates but susceptible to the Australian isolates.

The barley lines were separated into five groups based on cluster analysis (Fig. 2). Barley lines in group 1 were generally resistant but reacted differently, depending on the isolate used. In group 2, barley lines were moderately resistant to the Australian isolates and moderately susceptible to the Canadian isolates; lines in group 3 were moderately susceptible or susceptible to all isolates; lines in group 4 were resistant or moderately resistant to the Australian isolates and moderately susceptible or susceptible to the Canadian isolates; and lines in group 5 were moderately resistant to the Australian isolates and moderately susceptible to the Canadian isolates. There was a low correlation between seedling responses and adult responses, especially in Australia, where seedling and adult resistance largely appear independent of each other $\left(R^{2}=0.26, P=\right.$ $0.045)$. There was moderate correlation between field responses in Australia and with the Dillon isolate $\left(R^{2}=0.44, P=<0.001\right)$ and no correlation between field responses in Australia and with the 857WRS isolate $\left(R^{2}=0.24, P=0.227\right)$ in Canada.

Pathogenic variation of $P$. teres f. maculata isolates. Pathogenic variability was detected between the 19 isolates of $P$. teres $\mathrm{f}$. maculata, with 18 pathotypes identified (Table 1). Contrasting virulences were detected both between isolates from Australia and Canada and within isolates collected from the same continent. Pathotypes with virulence toward barley lines CBSS97M00830T-I2M-2Y-2M-1Y-1M=0Y and CI9214 were present among the Australian isolates but not among the Canadian isolates. However, pathotypes with virulence toward Dairokkaku, MXB.468, Skiff, and WI2553 were detected in Canada but not Australia. Of the 19 isolates, only the Australian isolates SNB113 and SNB281 had comparable virulence profiles. Isolates CI5791 and TR473 were generally avirulent toward the barley lines tested, while the Leduc and WAC9238 isolates were only virulent toward three and four barley lines, respectively. The remaining 15 isolates varied in virulence or avirulence profile toward 21 of the 24 barley lines.

SFNB severity on seedling, adult, and completely resistant barley cultivars in Victoria, Australia. Barque, which possesses the Ha4 resistance allele to SFNB, provided the best control of SFNB, with less than $1 \%$ of the area of the top four leaves affected at all three sites. Barque also had significantly lower AUDPC values and, with no difference in disease level between minimum and maximum disease treatments compared with the very susceptible Dash at Wonwondah in 2007 and 2008 (Table 2). This was not the

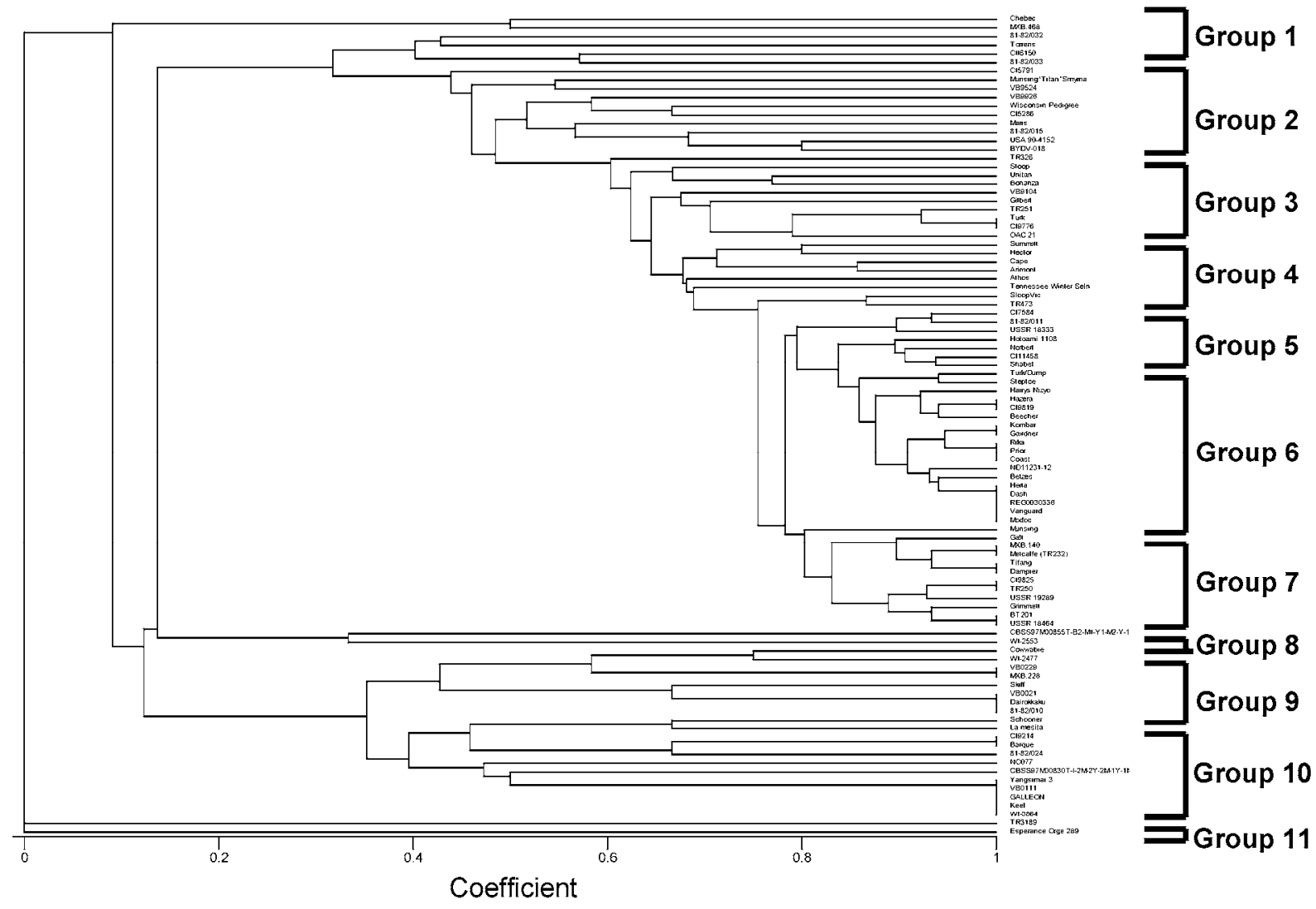

Fig. 1. Dendrogram showing the clustering of the resistance responses of 95 barley lines as seedlings towards 10 Australian and 9 Canadian isolates of Pyrenophora teres $f$. maculata using the unweighted pair-group method average. Experiments were carried out in glasshouses in Horsham, Australia and Lacombe, Canada. 
case at Horsham in 2007; however, AUDPC values were still very low when compared with the other cultivars and breeding line.

The two barley cultivars (Schooner and Cowabbie) and breeding line (VB9104) that had seedling or adult resistance were not as effective in controlling SFNB as Barque. The adult resistant line, VB9104, had significantly less infection than Dash at all three sites, with less than $3 \%$ of the top four leaves affected. AUDPC values for this line were also significantly less than Dash at two sites. The seedling resistant cultivars, Schooner and Cowabbie, provided better SFNB control at Wonwondah in 2007 and 2008 but had SFNB infection on the top four leaves and AUDPC values similar to Dash at Horsham in 2007. There were significant differences in disease levels between the minimum and maximum disease treatments for Schooner, Cowabbie, and VB9104 in some cases, whereas there were significantly lower disease levels with the minimum disease treatment versus the maximum disease treatment at all three sites for Dash.

Development of SFNB differed between the three field experiment sites. Infection was greatest at Wonwondah in 2007, followed by Wonwondah in 2008 and then Horsham in 2007. A high level of net form of net blotch (caused by P. teres f. teres) developed in the maximum disease treatment for Cowabbie at Wonwondah during 2008. All sites had low levels of scald (caused by R. secalis) and leaf rust (caused by Puccinia hordei). At each site, SFNB development was slow during the winter months (June to August) and rapid during the spring months (September to November).

Grain quality and yield. Grain quality of Dash was significantly reduced in the maximum disease-treated plots compared with the minimum disease-treated plots at Horsham in 2007 but, at Wonwondah in 2007 and 2008, the trend was not always significant (Table 3). Retention was also significantly reduced at Horsham in 2007 and in Wonwondah in 2008 in the adult resistant line VB9104 and in the seedling resistant Schooner. Cowabbie and Schooner had similar grain quality and grain yield between infected maximum disease- and minimum disease-treated plots at Horsham and Wonwondah in 2007 but grain quality was significantly reduced at Wonwondah in 2008. Barque had similar grain quality and grain yield between infected maximum disease- and minimum disease-treated plots at all sites, indicating that they were unaffected by SFNB. There were no differences in grain yield for any of the four barley cultivars or breeding line tested between infected maximum disease- and minimum disease-treated plots at all sites, indicating that grain yield was unaffected by SFNB infection.

\section{Discussion}

Barley lines that are resistant to SFNB at both the seedling and adult stages have been identified from a set of 95 breeding lines and cultivars. Esperance Orge 289 and TR3189 tested as seedlings were resistant to all Australian and Canadian isolates, while the cluster analysis identified the reaction response of these two lines as unique within this set of 95 barley lines. These lines may provide good seedling resistance and moderate adult resistance toward SFNB; however, further testing at the adult stage toward additional isolates is required to determine how effective these lines are toward the wider pathogen population.

Barley lines 81-82/010, Cowabbie, Dairokkaku, Galleon, Keel, MXB.228, MVB.468, NO077, Schooner, Skiff, Yarra, VB0111, VB0229, WI-2477, WI-2553, WI-3864, and Yangsimai 3 were resistant as seedlings to the Australian isolates but were moderately susceptible or susceptible to some Canadian isolates. These seedling resistances may potentially be useful in combination with other resistances; however, they could become ineffective if virulent pathotypes of Pyrenophora teres f. maculata increase in frequency. Cluster analysis of the seedling reactions placed most of these lines together (Fig. 1, groups 9 and 10, excluding MVB.468), indicating that they may share similar seedling resistance sources. Moreover, the seedling response reactions of these lines were clustered together with one or more of Keel, Barque, and Galleon, which have already been characterized, suggesting that the sources of seedling resistance in the 16 lines indicated above may not be novel.

Barley lines 81-82/033, Arimont, BYDV-018, CBSS97M00855TB2-M1-Y1-M2-Y-1M-0Y, CI9776, Keel, Sloop, Torrens, TR326,

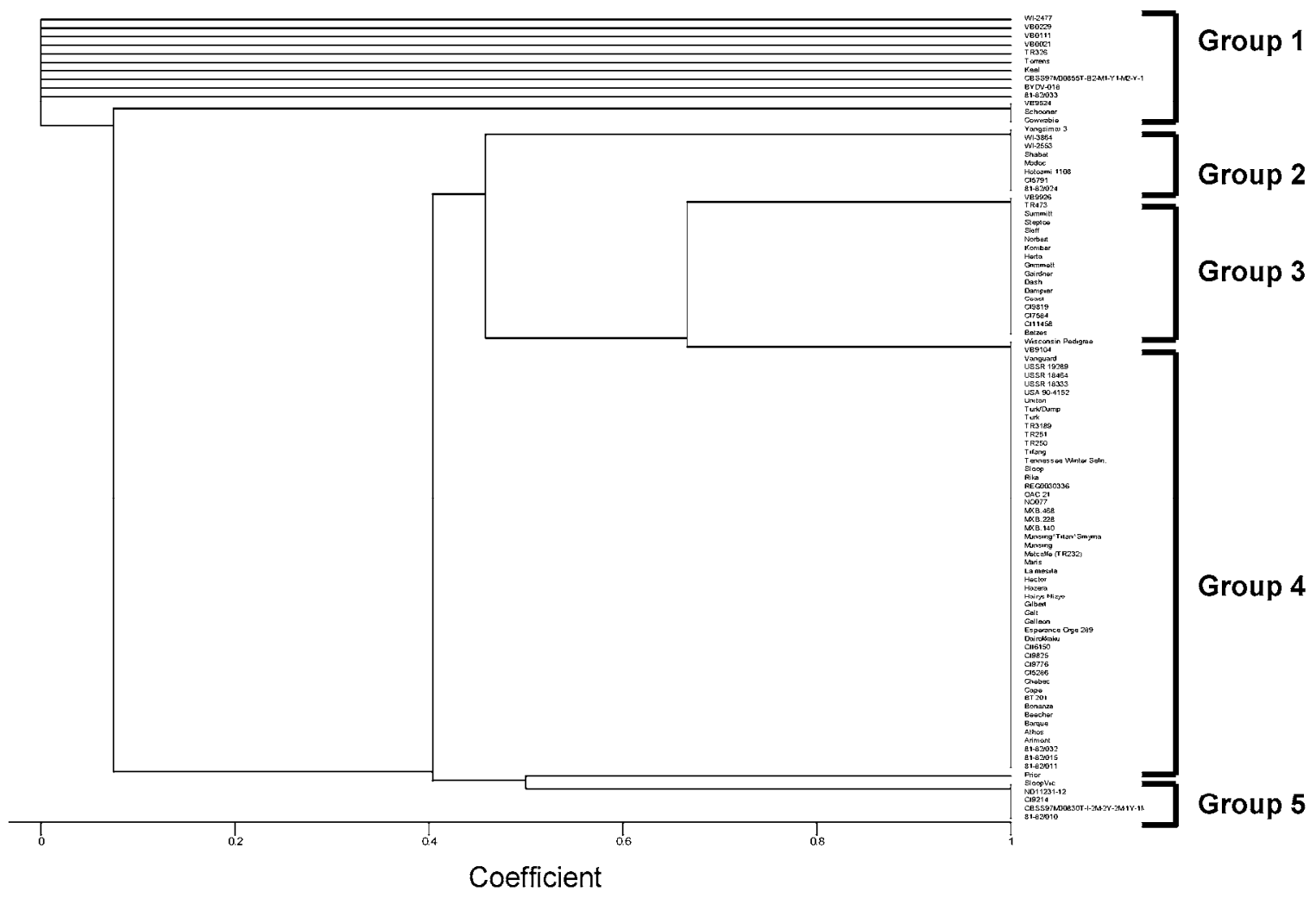

Fig. 2. Dendrogram showing the clustering of resistance responses of 95 barley lines as adults toward Australian and two Canadian isolates of Pyrenophora teres f. maculata using the unweighted pair-group method average. Experiments were carried out in the field near Horsham, Australia and Lacombe, Canada. 
Yarra, VB0111, VB0229, WI2477, WI2553, and Wisconsin Pedigree were resistant as adults toward the Australian and Canadian isolates of $P$. teres f. maculata tested. These lines are the best candidates for incorporating adult plant resistance into new barley cultivars. Lines 81-82/033, BYDV-018, CBSS97M00855T-B2-M1Y1-M2-Y-1M-0Y, Torrens, TR326, and WI2477 appeared to have unique resistance responses because they were clustered in group 1 in Figure 2. Lines Yarra, VB0111, and VB0229 also appeared in group 1 but are likely to possess the same resistance source as other previously characterized barley lines such as Keel and Barque (D. Moody, personal communication).
The barley lines CI9819 and TR251 were susceptible to many isolates of $P$. teres f. maculata, suggesting that they may be less reliable as resistance sources for barley breeders because isolates virulent toward them may be common in both countries. The remaining lines varied in their seedling and field responses but exhibited resistant-type reactions in some cases and, thus, are likely to possess partial resistance.

The high degree of pathogenic variation found among the 19 isolates was consistent with other studies $(4,6,11,12,20,24)$. The number of pathotypes identified in each study generally differs depending on the number of isolates and barley lines used. Some

Table 1. Pathogenic variation within 10 Australian and 9 Canadian isolates of Pyrenophora teres f. maculata according to reaction response in the greenhouse toward 24 barley lines as seedlings ${ }^{y}$

Isolate number $^{\mathbf{Z}}$

\begin{tabular}{|c|c|c|c|c|c|c|c|c|c|c|c|c|c|c|c|c|c|c|}
\hline Barley lines & $\begin{array}{l}\text { CI57 } \\
91^{\mathrm{C}}\end{array}$ & $\begin{array}{l}\text { TR4 } \\
7^{C}\end{array}$ & $\underset{\mathrm{C}}{\text { Leduc }}$ & $\begin{array}{c}\mathrm{AOC} \\
21^{\mathrm{C}}\end{array}$ & $\begin{array}{r}\mathbf{0 3 /} \\
\mathbf{0 5}^{\mathrm{A}} \\
\end{array}$ & $\begin{array}{c}\text { LO } \\
2^{233}\end{array}$ & $\begin{array}{c}857 \\
\text { WRS }^{\mathrm{C}}\end{array}$ & $\begin{array}{c}\text { SNB2 } \\
63^{\mathrm{A}}\end{array}$ & $\begin{array}{c}5 / 98 / 4 \\
\mathrm{~A}\end{array}$ & $\begin{array}{r}\text { WAC } \\
\text { 9238 }^{\mathrm{A}}\end{array}$ & $\begin{array}{c}\text { 04- } \\
\text { 0018 }^{\mathrm{A}}\end{array}$ & $\begin{array}{l}\text { WAC1 } \\
\text { 1153 }^{\mathrm{A}}\end{array}$ & $\begin{array}{l}\text { HRSO } \\
6022^{\mathrm{A}}\end{array}$ & $\begin{array}{c}\text { 04- } \\
\text { 0073 }^{\mathrm{A}}\end{array}$ & $\begin{array}{c}\text { LO } \\
262^{\mathrm{C}}\end{array}$ & $\begin{array}{c}\text { TR } \\
253^{C}\end{array}$ & $\begin{array}{l}\text { CDC } \\
\text { trey }^{C}\end{array}$ & $\begin{array}{c}\text { SNB1 } \\
13^{\mathrm{A}} \\
\text { and } \\
\text { SNB2 } \\
\mathbf{8 1}^{\mathrm{A}}\end{array}$ \\
\hline Pathotype number & 1 & 2 & 3 & 4 & 5 & 6 & 7 & 8 & 9 & 10 & 11 & 12 & 13 & 14 & 15 & 16 & 17 & 18 \\
\hline TR3189 & - & - & - & - & - & - & - & - & - & - & - & - & - & - & - & - & - & - \\
\hline Esperance Orge 289 & - & - & - & - & - & - & - & - & - & - & - & - & - & - & - & - & - & - \\
\hline Keel & - & - & - & - & - & - & - & - & - & - & - & - & - & - & - & - & - & - \\
\hline MXB.468 & - & - & - & - & - & - & + & - & - & - & - & - & - & - & - & - & - & - \\
\hline $\begin{array}{l}\text { CBSS97M00830T- } \\
\text { I-2M-2Y-2M-1Y- }\end{array}$ & & & & & & & & & & & & & & & & & & \\
\hline $1 \mathrm{M}=\mathrm{OY}$ & - & - & - & - & - & - & - & - & - & - & - & - & + & - & - & - & - & - \\
\hline CI9214 & - & - & - & - & - & - & - & - & - & - & - & - & - & - & - & - & - & + \\
\hline Dairokkaku & - & + & - & + & - & - & - & - & - & - & - & - & - & - & - & - & - & - \\
\hline Skiff & - & - & - & + & - & - & + & - & - & - & - & - & - & - & - & - & - & - \\
\hline WI-2553 & - & ns & - & - & - & - & - & - & - & - & - & - & - & - & + & - & - & - \\
\hline CI5791 & - & - & + & + & - & - & + & - & + & - & - & - & + & - & - & + & + & - \\
\hline Chebec & - & - & - & - & - & - & + & - & - & - & - & - & - & - & - & - & - & + \\
\hline $\begin{array}{l}\text { CBSS97M00855T- } \\
\text { B2-M1-Y1-M2-Y- }\end{array}$ & & & & & & & & & & & & & & & & & & \\
\hline 1M-0Y & - & - & - & - & + & - & - & - & - & - & - & - & - & - & + & - & - & + \\
\hline $81-82 / 033$ & - & - & - & - & - & - & - & - & - & - & - & - & - & + & + & + & + & + \\
\hline CI5286 & - & - & - & + & + & + & + & + & - & - & - & + & - & + & - & + & + & + \\
\hline Torrens & - & - & - & - & - & + & + & - & - & - & - & - & - & - & - & + & + & + \\
\hline Wisconsin Pedigree & - & ns & - & + & + & + & - & - & - & - & + & - & - & + & - & + & + & + \\
\hline CII6150 & - & - & - & - & - & + & - & - & - & - & - & + & + & - & + & + & + & + \\
\hline TR326 & - & - & - & - & + & + & + & + & + & - & + & + & + & - & - & - & + & + \\
\hline VB9104 & - & ns & - & - & - & - & - & + & + & + & + & + & + & - & + & + & + & + \\
\hline BYDV-018 & - & - & - & + & + & + & + & - & - & - & - & - & - & - & + & + & + & + \\
\hline CI9776 & - & - & - & - & + & + & - & + & + & + & + & + & + & + & + & - & + & + \\
\hline TR250 & - & - & - & + & + & + & - & + & + & - & + & + & + & + & + & + & + & + \\
\hline Arimont & - & - & + & - & + & + & + & - & - & + & + & + & + & + & + & + & + & - \\
\hline Kombar & + & - & + & + & + & + & + & + & + & + & + & + & + & + & + & + & + & + \\
\hline
\end{tabular}

y Symbols: $-=$ resistant, scores, 1 to $5 ;+=$ susceptible, scores 5.1 to 9 ; and ns $=$ no score.

${ }^{\mathrm{z}}$ Isolate number followed by A = Australian isolate and $\mathrm{C}=$ Canadian isolate.

Table 2. Severity of spot form of net blotch (SFNB) and area under the disease progress curve (AUDPC) values of four barley cultivars and one breeding line at three sites in Victoria, Australia during 2007 and $2008^{\mathrm{y}}$

\begin{tabular}{|c|c|c|c|c|c|c|c|c|c|c|c|c|}
\hline \multirow[b]{3}{*}{$\operatorname{Lines}^{\mathrm{z}}$} & \multicolumn{6}{|c|}{ SFNB severity (\%) } & \multicolumn{6}{|c|}{ AUDPC } \\
\hline & \multicolumn{2}{|c|}{ Horsham 2007} & \multicolumn{2}{|c|}{ Wonwondah 2007} & \multicolumn{2}{|c|}{ Wonwondah 2008} & \multicolumn{2}{|c|}{ Horsham 2007} & \multicolumn{2}{|c|}{ Wonwondah 2007} & \multicolumn{2}{|c|}{ Wonwondah 2008} \\
\hline & Max & Min & Max & Min & Max & Min & Max & Min & Max & Min & Max & Min \\
\hline Barque & 0.2 & 0.1 & 0.6 & 0.1 & 0.2 & 0.1 & 8 & $3 *$ & 12 & 4 & 13 & 2 \\
\hline Schooner & 0.7 & 0.7 & 2.3 & $0.8^{*}$ & 3.8 & $0.3^{*}$ & 15 & 13 & 40 & 15 & 89 & $8^{*}$ \\
\hline VB9104 & 1.1 & 1.1 & 2.3 & $0.4^{*}$ & 1.8 & 0.1 & 17 & $6^{*}$ & 37 & 9 & 45 & $7 *$ \\
\hline Cowabbie & 1.3 & $0.4^{*}$ & 2.4 & $0.6^{*}$ & 2.6 & $0.2^{*}$ & 22 & $8^{*}$ & 38 & $21 *$ & 60 & $10^{*}$ \\
\hline Dash & 1.5 & $0.4^{*}$ & 11.9 & $1.4^{*}$ & 4.0 & $0.3^{*}$ & 35 & $14 *$ & 155 & $21 *$ & 69 & $12 *$ \\
\hline$P$ & $<0.001$ & $<0.001$ & $<0.001$ & $<0.001$ & $<0.001$ & $<0.001$ & $<0.001$ & $<0.001$ & $<0.001$ & $<0.001$ & 0.013 & $<0.001$ \\
\hline LSD & 0.28 & 0.11 & 1.55 & 0.20 & 0.88 & 0.11 & 7.2 & 3.4 & 60.3 & 6.5 & 25.2 & 1.4 \\
\hline
\end{tabular}

${ }^{\mathrm{y}} \mathrm{Max}=$ maximum disease treatment established through the application of barley stubble, naturally infected with Pyrenophora teres f. maculata, at 3 t/ha, and no foliar fungicide applied; Min = minimum disease treatment established through the application of uninfected wheat stubble at 3 t/ha and applications of foliar fungicide (propiconazole [ $250 \mathrm{~g} / \mathrm{liter}$ applied at $250 \mathrm{ml} / \mathrm{ha}$ ) at 14 - to 18 -day intervals, starting at seedling stage and finishing at plant senescence; $*$ significantly lower $(P \leq 0.05)$ than the maximum disease mean.

${ }^{\mathrm{z}} P=$ the probability associated with the $F$ value in the analysis of variance and LSD $=$ Fisher's protected least significant difference $(\alpha=0.05)$ for barley means. 
differences in reaction responses were observed between this study and those conducted by Bockelman et al. (4), Gupta and Loughman (7), Karki and Sharp (11), and Tekauz (20). This can be explained by the slightly different screening conditions, isolates, and barley lines used in each study producing different host-pathogen interactions.

Virulence was detected in Australian isolates toward 'Betzes', 'Herta', and 'Steptoe' in this study, which contrasts with findings of Gupta and Loughman (7). This suggests the presence of different pathotypes between eastern and western Australia. However, it appears that these pathotypes have developed virulence toward only some resistance sources because the reaction responses of some barley lines (CI5791, CI7584, CI9819, Unitan, Arimont, and Steptoe) were similar to those reported in 1983 (4).

The high degree of pathogenic variation in the P. teres f. maculata population suggests that the development of barley cultivars with durable resistance will require a combination of multiple genes conferring minor or major effect. This strategy will poten- tially require several barley lines to be crossed to get the desired combination of resistance genes in a single breeding line.

In addition, durable resistance may be achieved by selecting lines that lack sensitivity genes, as well as incorporating resistance genes. This system has been demonstrated for other similar pathosystems which appear to have an inverse "gene-for-gene" interaction with toxin-encoding genes in the fungus and complementary sensitivity genes in the host. Understanding more about the barley$P$. teres f. maculata pathosystem is extremely important in determining the effectiveness and durability of resistance genes (Faris 2010; Friesen et al. 2007; Tan et al. 2010). This will require identification of the genes that confer susceptibility in the host and the corresponding host-selective toxins (effectors) in P. teres f. maculata.

A comprehensive investigation of pathogenic variation in the worldwide $P$. teres f. maculata population is required. This can be achieved using an international differential set of barley lines, such as the one recently developed for P. teres f. teres (1), that does not

Table 3. Grain quality (retention, screenings, and 1,000-grain-weight) and grain yield of four barley cultivars and one breeding line at three sites in the Wimmera region of Victoria, Australia in response to spot form of net blotch infection in 2007 and $2008^{z}$

\begin{tabular}{|c|c|c|c|c|c|c|c|c|c|}
\hline \multirow[b]{2}{*}{ Cultivar } & \multirow[b]{2}{*}{ Location } & \multicolumn{2}{|c|}{ Retention $(\%>2.5 \mathrm{~mm})$} & \multicolumn{2}{|c|}{ Screenings $(\%<2.2 \mathrm{~mm})$} & \multicolumn{2}{|c|}{ 1,000-grain-weight (g) } & \multicolumn{2}{|c|}{ Yield (t/ha) } \\
\hline & & Max & Min & Max & Min & Max & Min & Max & Min \\
\hline \multirow[t]{3}{*}{ Barque } & Horsham 07 & 95 & 95 & $<1$ & $<1$ & 43 & 43 & 3.4 & 3.4 \\
\hline & Wonwondah 07 & 92 & 93 & 1 & 1 & 43 & 43 & 5.3 & 5.1 \\
\hline & Wonwondah 08 & 80 & 83 & 2 & 1 & 48 & 48 & 3.5 & 3.5 \\
\hline \multirow[t]{3}{*}{ VB9104 } & Horsham 07 & $90 *$ & 95 & $<1$ & $<1$ & 42 & 41 & 3.4 & 3.5 \\
\hline & Wonwondah 07 & 87 & 88 & 2 & 2 & 43 & 43 & 5.1 & 5.1 \\
\hline & Wonwondah 08 & 83 & 84 & 2 & 2 & 49 & 49 & 3.4 & 3.4 \\
\hline \multirow{3}{*}{ Cowabbie } & Horsham 07 & 93 & 95 & $<1$ & $<1$ & 41 & 41 & 3.2 & 3.2 \\
\hline & Wonwondah 07 & 82 & 83 & 2 & 2 & 40 & 40 & 5.0 & 5.1 \\
\hline & Wonwondah 08 & $79 *$ & 70 & 2 & 2 & 42 & 41 & 3.4 & 3.4 \\
\hline \multirow[t]{3}{*}{ Schooner } & Horsham 07 & 91 & 91 & $<1$ & $<1$ & 40 & 39 & 3.1 & 3.2 \\
\hline & Wonwondah 07 & 84 & 84 & 2 & 2 & 41 & 41 & 4.6 & 4.6 \\
\hline & Wonwondah 08 & $56^{*}$ & 55 & 6 & 6 & 41 & 40 & 3.9 & 4.2 \\
\hline \multirow[t]{3}{*}{ Dash } & Horsham 07 & $67 *$ & 75 & $2 *$ & 1 & $36^{*}$ & 37 & 3.6 & 3.7 \\
\hline & Wonwondah 07 & 55 & 63 & $7 *$ & 3 & 37 & 37 & 5.6 & 5.4 \\
\hline & Wonwondah 08 & 57 & 61 & 5 & 4 & 38 & 37 & 3.4 & 3.6 \\
\hline
\end{tabular}

${ }^{\mathrm{z}}$ Max = maximum disease treatment established through the application of barley stubble, naturally infected with Pyrenophora teres f. maculata, at 3 t/ha, and no foliar fungicide applied; Min = minimum disease treatment established through the application of uninfected wheat stubble at 3 t/ha and applications of foliar fungicide (propiconazole [250 g/liter] applied at $250 \mathrm{ml} / \mathrm{ha}$ ) at 14- to 18-day intervals, starting at seedling stage and finishing at plant senescence; and $*=$ significantly higher than the minimum disease treatment, $P<0.05$.

Table 4. Proposed set of differential barley lines for Pyrenophora teres f. maculata

\begin{tabular}{|c|c|c|}
\hline Barley line & $\begin{array}{l}\text { Resistance gene or } \\
\text { allele }^{y}\end{array}$ & Rationale for inclusion \\
\hline Arimont & - & Moderate adult resistance toward Australian and Canadian isolates \\
\hline CI5286 & - & Adult resistance toward Australian isolates \\
\hline CI5791 & - & Moderate resistance toward Australian and North American isolates \\
\hline CI9214 or Galleon ${ }^{2}$ & Rpt4 & $\begin{array}{l}\text { Seedling resistance and moderate adult resistance on chromosome } 7 \mathrm{H} \text { toward Australian and Canadian } \\
\text { isolates identified by Williams et al. }(22,23)\end{array}$ \\
\hline $\mathrm{CI} 3576$ & Ha4 allele & Moderate resistance on chromosome $5 \mathrm{H}$ identified by Arabit et al. (3) \\
\hline CI9776 & - & Moderate adult resistance toward Australian and Canadian isolates \\
\hline CI9819 & Rpt6 & Adult resistance gene identified on chromosome $5 \mathrm{H}$ identified by Manninen et al. (13) \\
\hline CI9831 & - & $\begin{array}{l}\text { Seedling and adult resistance on chromosome } 2 \mathrm{H} \text { toward Canadian isolates identified by Ho et al. (9) } \\
\text { and Molnar et al. (16) }\end{array}$ \\
\hline CII6150 & - & Adult resistance to Australian isolates \\
\hline Chebec & - & Seedling resistance gene on chromosome $7 \mathrm{H}$ identified by Williams et al. (23) \\
\hline Dairokkaku & - & Adult resistance toward Australian isolates \\
\hline Esperance Orge 289 & - & Seedling and adult resistance toward Australian isolates; moderate resistance toward Canadian isolates \\
\hline Gairdner or Kombar ${ }^{\mathrm{Z}}$ & - & Susceptible control \\
\hline Haruna Nijo & - & Adults resistance genes identified on chromosomes $7 \mathrm{H}, 5 \mathrm{H}$, and $4 \mathrm{H}$ by Williams et al. (23) \\
\hline Keel & Ha4 allele & Resistance identified on chromosomes $7 \mathrm{H}, 5 \mathrm{H}, 4 \mathrm{H}, 2 \mathrm{H}$, and $1 \mathrm{H}$ by Arabi et al. (3) \\
\hline Skiff & - & Seedling resistance toward Australian isolates \\
\hline Torrens & - & Adult resistance toward Australian and Canadian isolates \\
\hline TR250 & QRpt7, QRpt6, QRpt4 & $\begin{array}{l}\text { Resistance genes identified on chromosomes } 7 \mathrm{H}, 6 \mathrm{H}, 4 \mathrm{H} \text {, and } 3 \mathrm{H} \text { by Grewel et al. (6) and } \\
\text { Gupta et al. (7) }\end{array}$ \\
\hline TR326 & - & Adult resistance toward Australian and Canadian isolates \\
\hline
\end{tabular}

y Symbol: $-=$ unknown.

${ }^{\mathrm{z}}$ Lines with the same resistance can be substituted. 
currently exist. Such a differential set is required and, ideally, would consist of between 10 and 15 lines, with each line possessing different resistance genes. These lines need to be diverse enough to differentiate between pathotypes within given pathogen populations and provide information on the pathogenic structure of the worldwide population. Currently, there is insufficient knowledge of the genetics of resistance in most of the barley lines used in this study and, as a result, the proposed differential set will be based on reaction response information that is currently available. From this study, we suggest an initial differential set (Table 4) that can be modified following further testing using a more extensive set of isolates from various continents and characterization of the resistance genes present. This initial set consists of 19 barley lines representing the groupings identified in the cluster analysis (Figs. 1 and 2) and lines that have been shown to have differential resistance in previous studies. Lines that have been shown to have differential resistance in previous studies but are generally susceptible in this study have been omitted but could also potentially be included (CI11458, CI7584, CI9825, Steptoe, and Summit). Breeding lines Chebec, CI9214 or Galleon, Haruna Nijo, and CI9831 should also be included because these resistance sources have been characterized genetically in previous studies $(5,9,16,23)$.

More isolates will need to be tested to accurately establish the virulence spectra of $P$. teres f. maculata in Australia. This has previously been done in some detail in other barley-growing regions of the world such as Canada, the United States, and the Mediterranean region $(4,11,20)$. However, given that this fungus reproduces sexually and complex pathotype structures have previously been identified (20), it is likely that new pathotypes will evolve.

The current study showed that sources of resistance that confer complete resistance type reactions can be used to effectively manage SFNB in the Wimmera region of Victoria, Australia. Barque provided the best control at all three field experiment sites, with less than $1 \%$ of the top four leaves affected by SFNB. Barque is known to possess a resistance gene found on chromosome $5 \mathrm{H}$ (3) which also confers cereal cyst nematode resistance. This resistance source is readily available to barley breeders and may be the most appropriate resistance source in the short term for incorporation into malt-quality barley cultivars.

The barley cultivars and lines that possessed resistance genes that conferred seedling or adult resistance, such as Schooner, VB9104, and Cowabbie, also provided reductions in SFNB severity; however, disease control was variable and, in some cases, did not completely prevent reductions to grain quality. As a consequence, these sources of resistance may need to be combined with other resistance genes to provide adequate control of SFNB in malt-quality barley cultivars. Alternatively, other management strategies such as foliar fungicide application may be necessary where disease pressure is high.

The current study determined that SFNB caused insignificant yield losses in the Wimmera region of Victoria, even when the growing season was characterized by sustained precipitation events throughout the spring months and high SFNB severity was recorded (Wonwondah during 2007). These results contrasted with those from Western Australia (10) that found that SFNB caused significant grain yield losses. This highlights the need to test barley cultivars with seedling and adult resistance in other barley-growing regions to determine their respective yield, because they are likely to respond differently in other environments.

\section{Acknowledgments}

We thank C. Grimes, T. T. Angessa, S. Gupta, D. Moody, and D. Watson for providing seed and information on phenotypic response of barley lines; S. Gupta and F. Keiper for isolates of Pyrenophora teres f. maculata; G. Exell, J. Bretag, D. Ward, and S. Andrews for technical assistance with field and glasshouse experiments at Horsham and Wonwondah, Australia; N. Rauhala, J. Busaan, D. Clark, L. Schnepf, and B. Bant for technical assistance with field and glasshouse experiments at Lacombe Research Centre of Agriculture and Agri-Food Canada; the Cereal Grains Chemistry team at Department of Primary Industries, Horsham for NIR analyses and protein testing; Grains Research and Development
Corporation for funding projects IST-50 and DAV00087; Victoria Department of Primary Industries for funding and support; the Lacombe Research Centre, Agriculture and Agri-Food Canada for in-kind support during M. McLean's 3month research exchange in 2008; J. Smith and D. Partington for assistance with statistical analyses; and J. Edwards for providing comment on this manuscript.

\section{Literature Cited}

1. Afanasenko, O. S., Jalli, M., Pinnschmidt, H. O., Filatova, O., and Platz, G. J. 2009. Development of an international standard set of barley differential genotypes for Pyrenophora teres f. teres. Plant Pathol. 58:665-676.

2. Arabi, M. I. E., Al-Safadi, B., and Charbaji, T. 2003. Pathogenic variation among isolates of Pyrenophora teres, the causal agent of barley net blotch. J. Phytopathol. 151:376-382.

3. Arabi, M. I. E., Barrault, G., Sarrafi, A., and Albertini, L. 1992. Variation in the resistance of barley cultivars and in the pathogenicity of Drechslera teres $\mathrm{f}$. sp. maculata and $D$. teres $\mathrm{f}$. sp. teres isolates from France. Plant Pathol. 41:180-186.

4. Bockelman, H. E., Sharp, E. L., and Bjarko, M. E. 1983. Isolates of Pyrenophora teres from Montana and the Mediterranean region that produce spottype lesions on barley. Plant Dis. 67:696-697.

5. Friesen, T. L., Faris, J. D., Lai, Z., and Steffenson, B. J. 2006. Identification and chromosomal location of major genes for resistance to Pyrenophora teres in a doubled-haploid barley population. Genome 49:855-859.

6. Grewal, T. S., Rossnagel, B. G., and Scoles, G. J. 2008. The utility of molecular markers for barley net blotch resistance across geographic regions. Crop Sci. 48:2321-2333.

7. Gupta, S., and Loughman, R. 2001. Current virulence of Pyrenophora teres on barley in Western Australia. Plant Dis. 85:960-966.

8. Herrmann, A., Lower, C. F., and Schachtel, G. A. 1999. A new tool for entry and analysis of virulence data for plant pathogens. Plant Pathol. 48:154158.

9. Ho, K. M., Tekauz, A., Choo, T. M., and Martin, R. A. 1996. Genetic studies on net blotch resistance in barley cross. Can. J. Plant Sci. 76:715-719.

10. Jayasena, K. W., van Burgel, A., Tanaka, K., Mejewski, J., and Loughman, R. 2007. Yield reduction in barley in relation to spot-type net blotch. Aust. Plant Pathol. 36:429-433.

11. Karki, C. B., and Sharp, E. L. 1986. Pathogenic variation in some isolates of Pyrenophora teres f. sp. maculata on barley. Plant Dis. 70:684-687.

12. Khan, T. N. 1982. Occurrence and pathogenicity of Drechslera teres isolates causing spot-type symptoms on barley in Western Australia. Plant Dis. 66:423-425.

13. McLean, M. S., Howlett, B. J., and Hollaway, G. J. 2009. Epidemiology and control of spot form of net blotch (Pyrenophora teres f. maculata) of barley: a review. Crop Pasture Sci. 60:303-315.

14. McLean, M. S., Howlett, B. J., and Hollaway, G. J. 2010. Spot form of net blotch, caused by Pyrenophora teres f. maculata, is the most prevalen foliar disease of barley in Victoria, Australia. Aust. Plant Pathol. 39:46-49.

15. Manninen, O. M., Jalli, M., Kalender, R., Schulman, A., Afanasenko, O., and Robinson, J. 2007. Mapping of major spot-type and net-type net-blotch resistance genes in the Ethiopian barley line CI9819. Genome 49:15641571

16. Molner, S. J., James, L. E., and Kasha, K. J. 2000. Inheritance and RAPD tagging of multiple genes for resistance to net blotch in barley. Genome 43:224-231.

17. Neher, D. A., Reynolds, K. L., and Campbell, C. L. 1997. Analysis of disease progress curves using linear models. Pages 29-33 in: Exercises in Plant Disease Epidemiology. L. J. Francl and D. A. Neher, eds. American Phytopathological Society, St. Paul, MN.

18. Panozzo, J. F., Eckermann, P. J., Mather, D. E., Moody, D. B., Black, C. K., Collins, H. M., Barr, A. R., Lim, P., and Cullis, B. R. 2007. QTL analysis of malting quality traits in two barley populations. Aust. J. Agric. Res. 58:858866.

19. Tekauz, A. 1985. A numerical scale to classify reactions of barley to Pyrenophora teres. Can. J. Plant Pathol. 7:181-183.

20. Tekauz, A. 1990. Characterisation and distribution of pathogenic variation in Pyrenophora teres f. teres and P. teres f. maculata from western Canada. Can. J. Plant Pathol. 12:141-148.

21. van den Berg, C. G. J., and Rossnagel, B. G. 1990. Effect of tilt on severity of spot-type net blotch, grain yield and yield components in barley. Can. J. Plant Sci. 70:473-480.

22. Williams, K. J., Lichon, A., Gianquitto, P., Kretschmer, J. M., Karakousis, A., Manning, S., Langridge, P., and Wallwork, H. 1999. Identification and mapping of a gene conferring resistance to the spot form of net blotch (Pyrenophora teres f. maculata) in barley. Theor. Appl. Genet. 99:323-327.

23. Williams, K. J., Platz, G. J., Barr, A. R., Cheong, J., Willsmore, K., Cakir, M., and Wallwork, H. 2003. A comparison of the genetics of seedling and adult plant resistance to the spot form of net blotch (Pyrenophora teres $\mathrm{f}$. maculata). Aust. J. Agric. Res. 54:1387-1394.

24. Wu, H. L., Steffenson, B. J., Oleson, A. E., and Zhong, S. 2003. Genetic variation for virulence and RFLP markers in Pyrenophora teres. Can. J. Plant Pathol. 25:82-90.

25. Zadoks, J. C., Chang, T. T., and Konzak, C. F. 1974. A decimal code for the growth stages of cereals. Weed Res. 14:415-442. 